\title{
MECHANICAL CHARACTERIZATION OF BONDED JOINTS MADE OF ADDITIVE MANUFACTURED ADHERENDS
}

\author{
D. K. K. Cavalcanti, M. D. Banea*, H. F. M. de Queiroz
}

Federal Center of Technological Education in Rio de Janeiro, Av. Maracanã, 229 - Bloco E - 5o andar CEP 20271-110, Rio de Janeiro - RJ - Brasil

*Corresponding author's e-mail address: mdbanea@gmail.com

\begin{abstract}
In this study, the mechanical behaviour of bonded joints made of additive manufactured (AM) adherends was experimentally investigated. Two different methods to increase the mechanical strength of the AM joints bonded with an epoxy adhesive were studied: the effect of modifying the geometry of the adherends along the overlap length (with a sinusoid interface) and the influence of two different print orientations (flatwise and edgewise direction) on the load capacity of 3D-printed parts bonded joints. Single lap-joints (SLJs) were tested for each case studied. Results showed an increase in load capacity of the joints by modifying the geometry of the adherends along the overlap length (the load capacity increased by $62 \%$ for flatwise and 36\% for edgewise print orientation). Modifying the morphology of the $3 D$-printed adherends surfaces in the overlap region had a more significant influence on the load capacity of the joints compared to modifying the print orientation of the $3 D$-printed parts.
\end{abstract}

KEYWORDS: Additive manufactured parts, Bonded joints, Surface morphology, Print-orientation.

\section{INTRODUCTION}

Additive manufacturing (AM) or 3D printing technology is a process in which 3D components, with high precision and complexity, are made by depositing materials in layer-by-layer fashion as opposed to conventional machining or forming methods [1]. AM has been called the next industrial revolution and has experienced a huge development in the last decade. The process starts with a 3D computer-aided design (CAD) model of the part to be manufactured, which is electronically sliced into a number of horizontal cross-sections. Next, this data is sent to AM machine where each cross-section is built one over the other to create a 3D part represented in 3D-CAD model [2]. However, instead of printing the entire product, 3D printing can be used to produce only the most complex parts, which can be further combined with simple, non-printed parts from other materials to make the final product [3]. Limited work is found in the literature that presents the joining of plastics parts fabricated with AM, specifically fused deposition modelling (FDM). FDM is a technology which enables to create functional parts with complex geometries by extruding a semi-molten polymer through a small-diameter nozzle. FDM parts can be considered as a laminated composite structure having vertically stacked layers of bonded beads. Thus, the mechanical properties of the FDM part depend on the quality of filament materials used and also on the part orientation and raster angle that produce the anisotropic nature of properties. In addition, other FDM processing parameters including: contour width, number of contours, raster width, raster to contour air gap, raster to raster air gap and slice height also play an important role in improving the mechanical properties of FDM-produced parts [4], [5].

FDM-produced parts have many promising applications. However, the relatively lower strength compared to that of the injection-moulded part still restricts their large applications.

One method to join additive manufactured parts is adhesive bonded method. Adhesively bonded joints are used in structural applications, especially in automotive and aerospace sectors, because of high strength to weight ratio, design flexibility, damage tolerance, fatigue resistance, etc. [6], [7], [8]. The single-lap joint is the most common joint used mainly due to its simplicity and efficiency. However, one of the problems associated to this joint is the fact that the stress distribution (shear and peel) is concentrated at the ends of the overlap [9]. It was shown in the literature that modifying the shape of adherends can reduce the peak values of shear and peel stresses in SLJ which can improve the overall strength of the joint. Several researchers have explored modifying 
the adherend geometries like tapering, stepping and wavy lap, as possible options to minimize the stress concentrations at the overlap end [6]. One of the methods investigated in the literature for strength improvement is mechanical interlocking between adherend and adhesive. This is beneficial to the overall SLJ strength, due to its characteristic crack arrestment, increased fracture toughness and higher bonded surface area for the same overlap [10]. However, mechanical interlocking is not easily achieved with conventional substrates (e.g. metal and fibre reinforced composites). FDM is a versatile fabrication method, which allows the design of more complex geometries of the substrates relatively easily, whereas conventional fabrication methods require complex machining of either substrate or moulds [2]. Spaggiari and Denti [11] used single lap joints SLJs) with two adhesives and seven different surface morphologies to study AM bonded joints. They found that the surface morphologies of the adherends had only a small influence on the load capacity and stiffness of the joints. Boss et al. [12] showed that modifying the shape of adherends can uniformize the shear and peel stress distribution along the overlap in SLJ which can improve the overall strength of the joint.

The objective of this study is to investigate the mechanical behaviour of bonded joints made of additive manufactured adherends. Two different methods to increase the mechanical strength of the AM joints bonded with an epoxy adhesive were studied: the effect of modifying the geometry of the adherends along the overlap length (sinusoid interface) and the influence of two different print orientations (flatwise and edgewise direction).

\section{MATERIALS AND METHODS}

\subsection{Materials}

All AM parts specimens were fabricated using a Graber I3 base Cartesian 3D printer, available at the laboratory of composites and adhesives (LADES, CEFET/RJ). The slicer program used to create the gcode was the free software Ultimaker Cura, Netherlands. The specimens were manufactured using the following parameters: nozzle temperature: $230^{\circ} \mathrm{C}$; bed temperature: $60{ }^{\circ} \mathrm{C}$; layer height: $0.25 \mathrm{~mm}$; infill density $100 \%$; print speed: $60 \mathrm{~mm} / \mathrm{s}$ and no active cooling.

The thermoplastic filament used was a Green Polylactic acid (PLA), supplied by Sethi3D (Campinas/SP, Brazil). Photos of AM fabricated specimens can be seen in figure 1. A two-component structural epoxy adhesive, BetamateTM2096, provided by Dow (Dow, Brazil) was selected as the adhesive material. The basic mechanical properties of the adhesive were determined in previous studies and are summarized in table 1.
Table 1. Tensile data of Betamate ${ }^{\mathrm{TM}} 2096$ adhesive [13], [14]

\begin{tabular}{|c|c|c|}
\hline $\begin{array}{c}\text { Young's modulus } \\
{[\mathrm{GPa}]}\end{array}$ & $\begin{array}{c}\text { Tensile strength } \\
{[\mathrm{MPa}]}\end{array}$ & $\begin{array}{c}\text { Tensile strain } \\
{[\%]}\end{array}$ \\
\hline 1.6 & 34 & $8 \%$ \\
\hline
\end{tabular}

\subsection{Adherend Fabrication}

The geometry of the SLJs specimens can be seen in figure 2. As no ASTM standard can be used with AM technology, the specimen dimensions used are based on ASTM 1002 standard [15]. All specimens were fabricated using the 3D printer and the same parameters as stated in section 2.1. The Solidworks CAD program was used to design the substrates.

Two configurations were considered: one without any interlocking mechanism, flat surface, (Group A) and the other with an interlocking mechanism in the form of a wave (Group B), as can be seen in figure $2 \mathrm{a}$ and $\mathrm{b}$. For each group, two different printing orientations, YXZ (Flatwise) and YZX (Edgewise), were investigated (Fig. 3). The flatwise adherends were printed in the $X Y$ plane where the $\mathrm{Z}$ axis is the thickness direction, resulting in a raster angle of $+45 /-45^{\circ}$ in a layer by layer configuration. On the other hand, the edgewise adherends were printed with the $\mathrm{Z}$ axis as the width direction and the number of walls was increased to 5 , thus resulting in a unidirectional material deposition parallel to the $\mathrm{Y}$ axis (a raster angle of $0^{\circ}$ ), as can be seen in figure 3 .

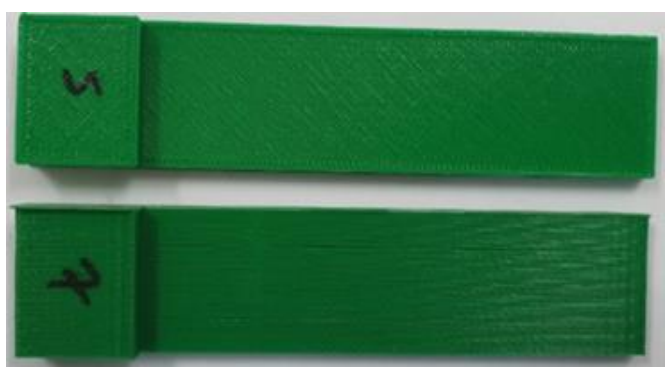

a)

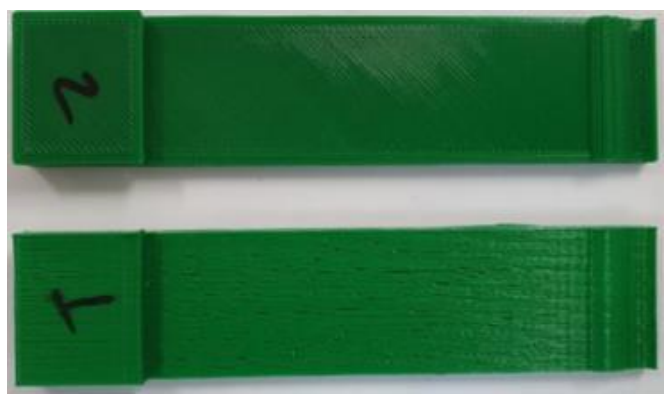

b)

Fig. 1. Photos of AM parts specimens: a) Group A and b) Group B (flatwise and edgewise) 


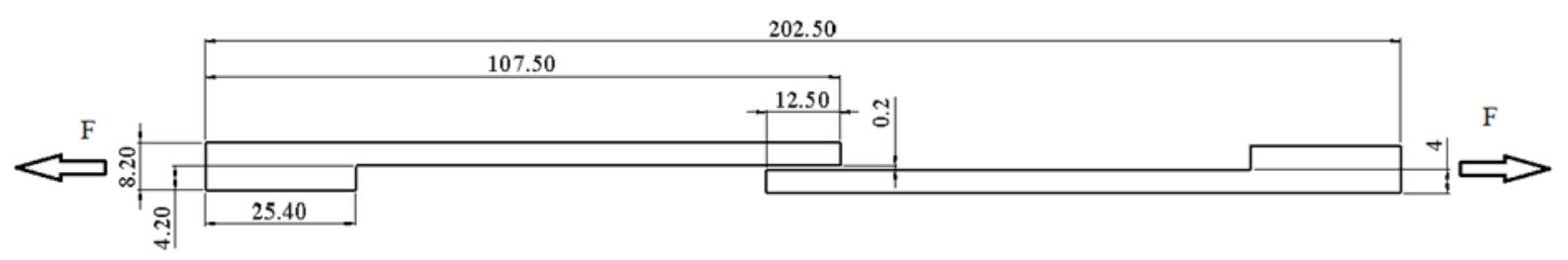

a)

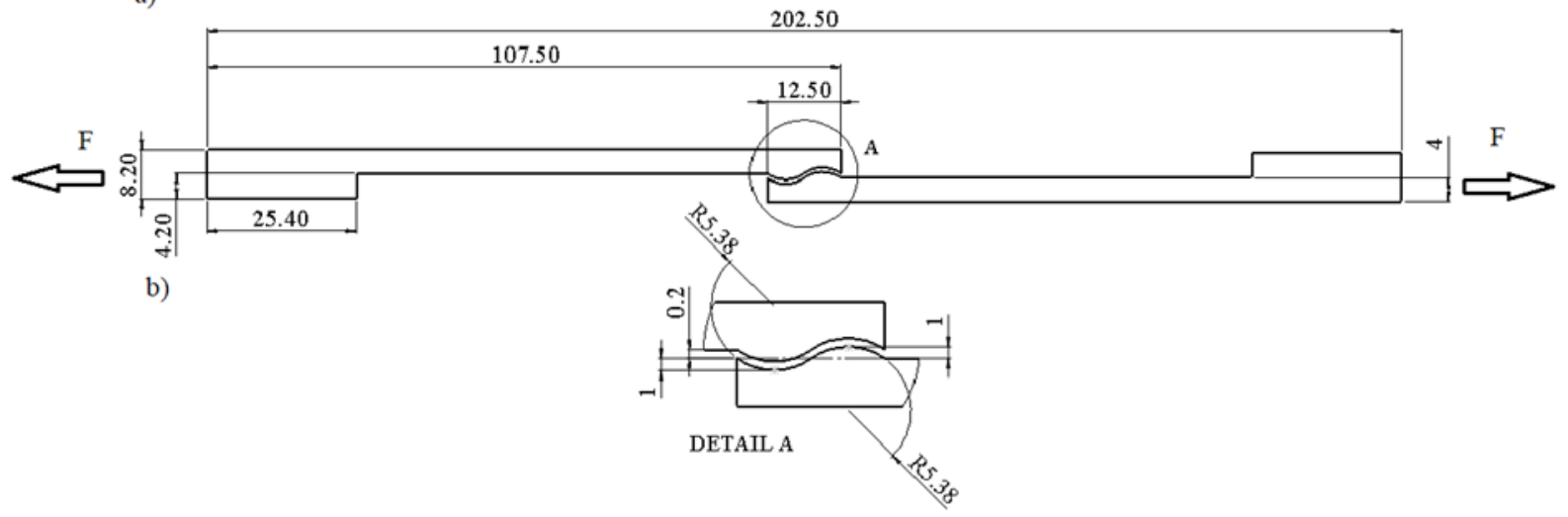

Fig. 2. SLJs specimen geometry [mm]: a) Group A, b) Group B

Table 2. SLJs results as printing orientation and overlap geometry

\begin{tabular}{|c|c|c|c|}
\hline \multicolumn{2}{|c|}{ Joint Type } & Load (N) & Displacement (mm) \\
\hline \multirow{2}{*}{ Group A } & Flatwise & $1202.45 \pm 49.97$ & $2.96 \pm 0.14$ \\
\cline { 2 - 4 } & Edgewise & $1838.21 \pm 121.56$ & $1.84 \pm 0.81$ \\
\hline \multirow{2}{*}{ Group B } & Flatwise & $3160.72 \pm 164.32$ & $2.94 \pm 0.44$ \\
\cline { 2 - 4 } & Edgewise & $2872.89 \pm 29.61$ & $2.61 \pm 0.39$ \\
\hline
\end{tabular}

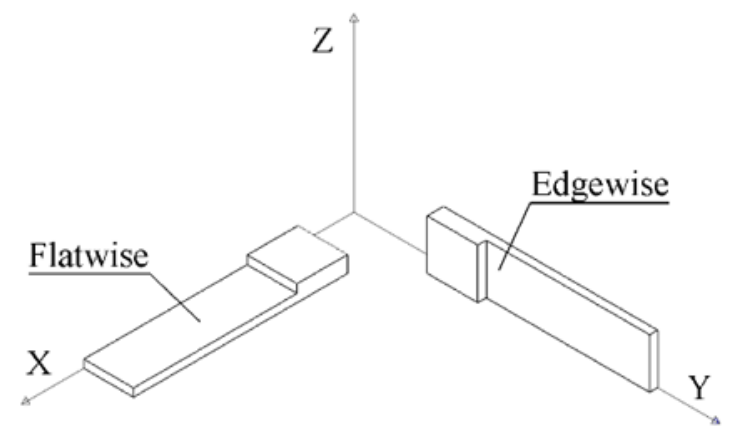

Fig. 3. Printing direction

\subsection{SLJ specimen fabrication}

A mould with spacers for correct alignment of the substrates was used (Fig. 4) [16]. The bondline thickness was $0.2 \mathrm{~mm}$ and was controlled by the substrate geometry as can be seen in figure 3 . The overlap length was $12.5 \mathrm{~mm}$. The dimension of a single adherend is $107.5 \mathrm{~mm} \times 25 \mathrm{~mm} \times 4 \mathrm{~mm}$ as can be seen in figure 2 .

Packing shims were also used to control bondline thickness. They were placed in the middle of the specimen, between the overlap and the tabs located at the end of the substrate.

All the adherend surfaces were initially degreased with acetone to remove the dust and to assure a clean surface. The adhesive was applied on the adherend surface and spread over it with a spatula. The joints were cured using a hot plate hydraulic press (model SL-12/20). The curing time of 2 hours at a temperature of $60^{\circ} \mathrm{C}$ was used, as recommended by the adhesive manufacturer.

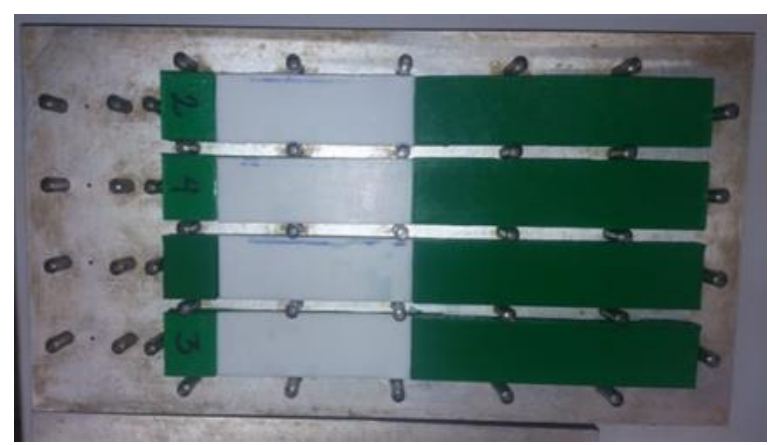

Fig. 4. SLJ specimen fabrication

\subsection{Test method}

The SLJ tests were performed at room temperature with a cross-head speed of $1 \mathrm{~mm} / \mathrm{min}$ using a testing machine (INSTRON ${ }^{\circledR}$ model 5966) with a capacity of $10 \mathrm{kN}$. At least 4 specimens were tested for each condition. Load-displacement curves were recorded 
during the test. The SLJ specimen test set-up is shown in figure 5 .

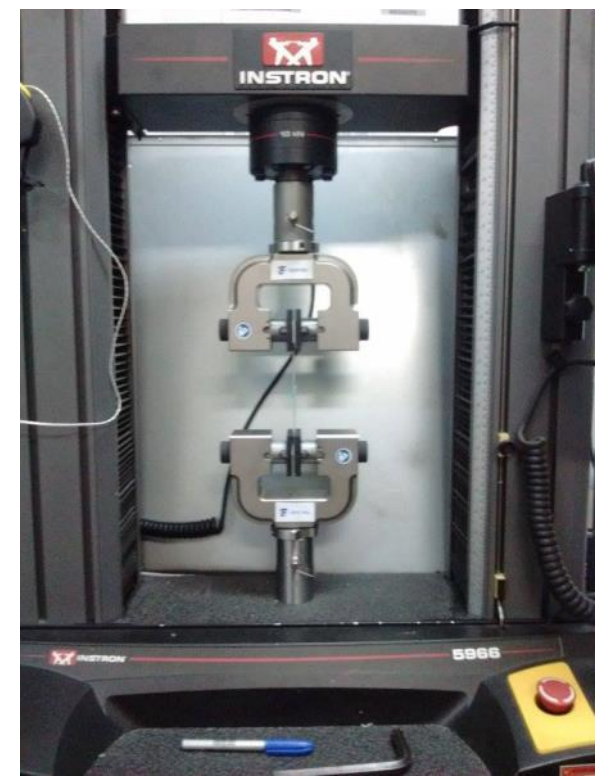

Fig. 5. SLJ specimen test set-up

\section{RESULTS AND DISCUSSION}

\subsection{Failure Modes}

The failure modes of the SLJ specimens were visually analyzed after testing. Figure 6 shows representative failure modes for the A and B Group specimens for both printing directions, while figure 7 presents their respective failure cross sections. As can be seen in figure 6 , most of the observed failures were adherend failure mode. The flatwise Group A presented adherend failure in the form of delamination roughly halfway through the adherend thickness (Fig. 6a).

The edgewise Group A presented adherend failures close to the overlap edge with a slight adhesive failure at the point of maximum bending. A similar situation was observed for the flatwise Group B, while for the edgewise Group B the adherend failures were at the overlap edge.

Figure 7 presents the failure cross sections of both groups $\mathrm{A}$ and $\mathrm{B}$. It can be seen in figure $7 \mathrm{a}$ that the failure of the flatwise A specimens was more ductile closer to the adherend/adhesive interface, evidenced by a whitening of the printed material. However, halfway through the adherend, this whitening fades and the normal colour can be seen, indicating a more brittle failure. Figure $7 \mathrm{~b}$ presents the failure cross section of the edgewise Group A. The failure presented was mostly brittle and the crack nucleated in two separate areas. Initially, close to the overlap edge, a crack initiated from the surface to the second layer, followed by a stabilization of this first crack until the final catastrophic adherend failure (see Fig. 8, for crack propagation example). In figure $7 \mathrm{~b}$, it is possible to observe a variation in smoothness of the failure surface (close to the edge and the adherend surface, the failure surface becomes very smooth and shiny, indicating a very brittle response). Towards the bonded interface, however, the failure surface becomes more irregular, indicating a more ductile behaviour. Figure $7 \mathrm{c}$ displays the cross section of the flatwise Group B. A slight whitening can still be seen; however, this failure seems to be mostly brittle. Figure $7 d$ presents the cross section of the edgewise Group B and a sharp ductile response on one side that gradually fades diagonally through the thickness of the adherend was observed.

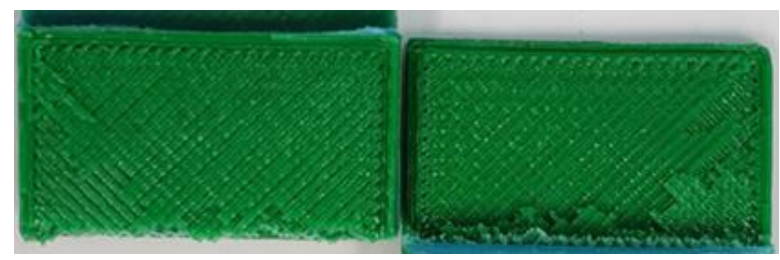

a)

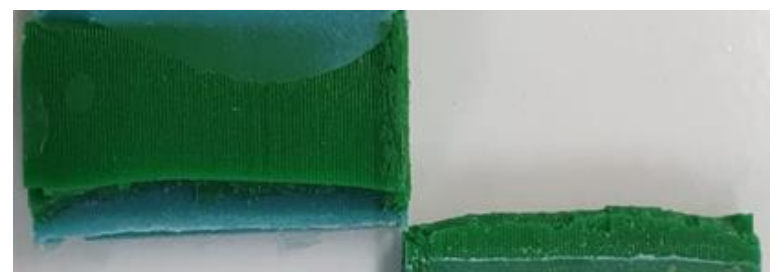

b)

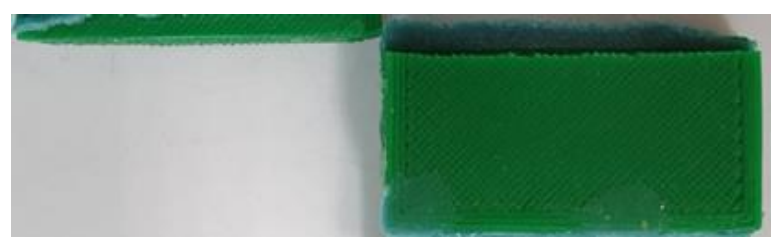

c)

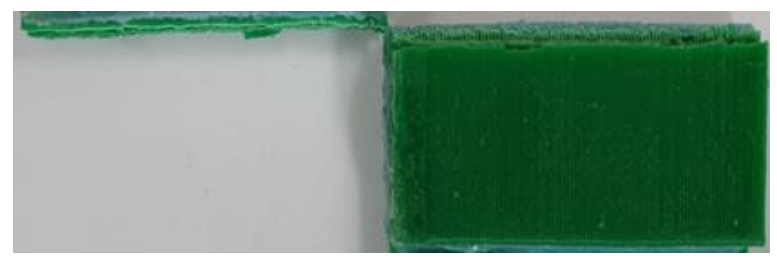

d)

Fig. 6. Representative failure modes for all joint groups: a) flatwise Group A, b) edgewise Group A, c) flatwise Group B, d) edgewise Group B

\subsection{Effect of Modifying the Geometry of the Overlap Region}

In table 2 and figure 9, it can be seen that Group B presented a significant increase in both average failure load and joint rigidity when compared to Group A joints (the maximum failure load increased by $62 \%$ for flatwise and $36 \%$ for edgewise configuration when compared to Group A (flat or conventional SLJ)). It was shown in the literature [17] that the wave geometry changes the values of the peak stresses at 
both ends of the overlap. This design not only avoids the load eccentricity common to SLJs but also allows the development of compressive stress at the end of the overlap. Thus, the increase in load capacity for the SLJ with modified surface morphology (Group B) might be explained by the addition of material near the overlap edge which leads to a better stress
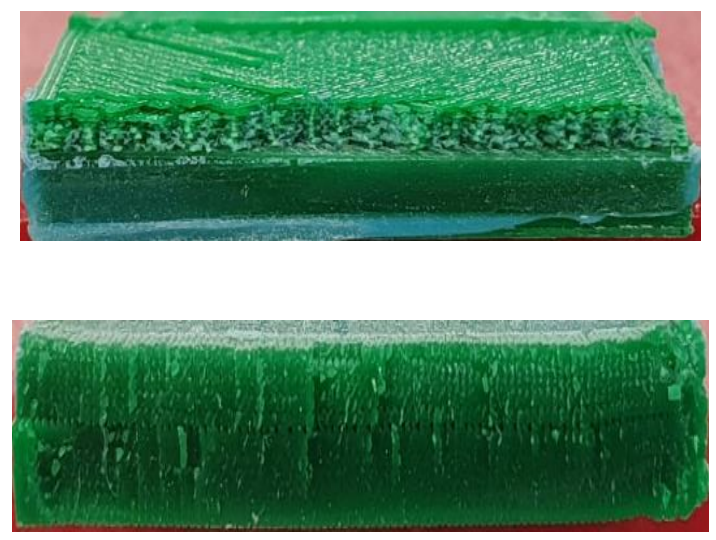

a)

b)

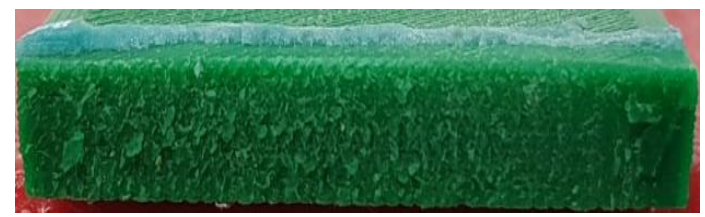

c)

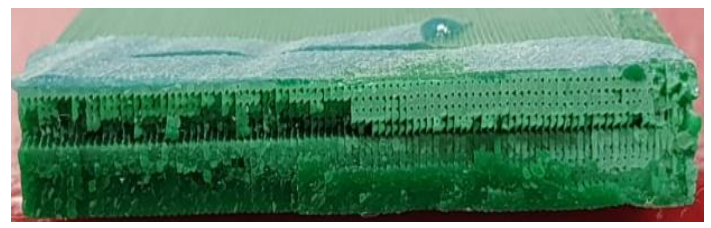

d)

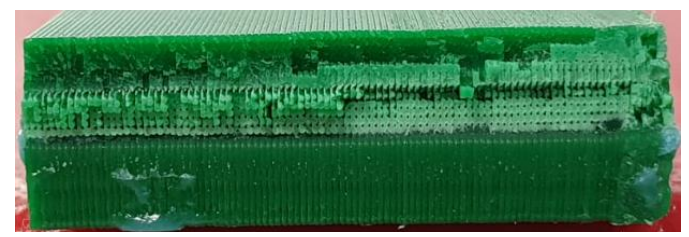

distribution in the overlap region and less edge rotation during testing. Avila and Bueno [18] showed by experimental and numerical studies on SLJs with wavy geometry using composite substrates, that using adherends with wavy shapes increased the strength of the joints by nearly $40 \%$ compared to the flat SLJ.
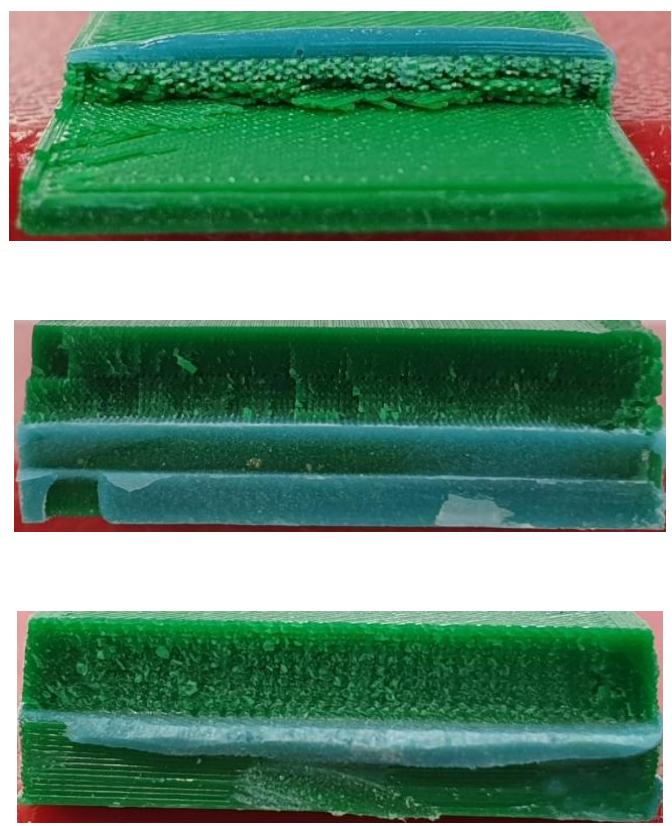

Fig. 7. Representative failure cross sections: a) flatwise Group A, b) edgewise Group A, c) flatwise Group B, d) edgewise Group B
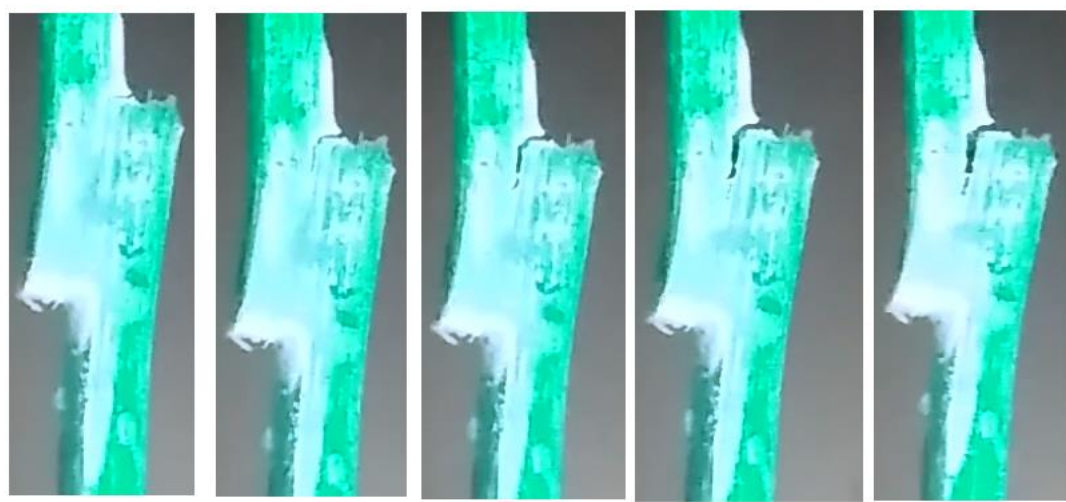

Fig. 8. Example of failure progression during loading of a specimen from edgewise Group A

\subsection{Effect of Printing Orientation}

In table 2 and figure 9, it can be seen that there was a significant variation of average failure load and joint rigidity as a function of print orientation for Group A. For instance, edgewise Group A presented an increase of average failure load of $35 \%$ compared to the flatwise Group A joints. The delamination failure of the flatwise 
Group A is the main reason of the lowest failure load, when compared to the complete adherend failure of other groups. It was shown in the literature that the adherend strength and rigidity is greatly affected by printing orientation $[19,20]$. Therefore, the edgewise Group A adherend joints had higher strength and stiffness than the flatwise adherend, resulting in a higher joint failure load capacity.

On the other hand, for Group B, the load capacity of flatwise printed adherends was higher (by
9\%) compared to edgewise printed parts. This may be explained by the different surface morphology of the adherends, which seems to minimize the effect of print orientation for this specific case. Another explanation is that there was a slight difference in the print quality between flatwise and edgewise print orientations for Group B specimens (the edgewise print orientation specimens presented some air gaps between the filaments).

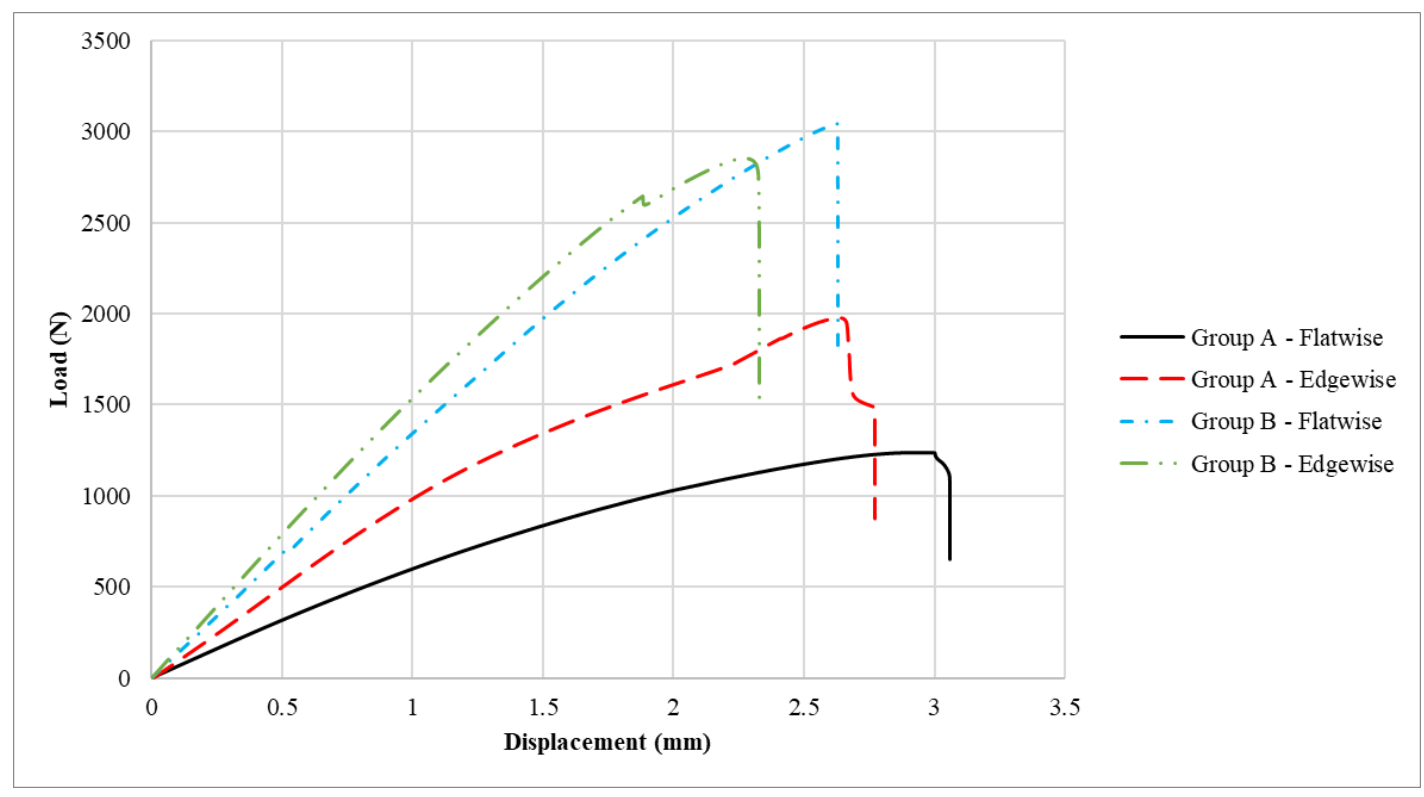

Fig. 9. Representative load-displacement curves for all groups studied

\section{CONCLUSIONS}

In this study, the mechanical behaviour of bonded joints made of AM adherends was investigated. Two different methods to increase the load capacity of the joints were studied: modifying the surface morphology of the overlap region and changing the print orientation of the adherends. The following conclusions can be drawn:

- The structural adhesive used presented good adhesion between the PLA adherends for all conditions studied. The failure modes were all adherend failure mode at the edge of the overlap, with the exception of the flatwise Group A that presented partial adherend failures halfway through the thickness.

- By modifying the morphology of the adherend surfaces in the overlap region, the load capacity and stiffness of the joints were significantly improved compared to the conventional (flat) SLJ (the load capacity increased by $62 \%$ for flatwise and $36 \%$ for edgewise printorientation).

- The print orientation of the adherends also affects the load capacity of the SLJ. However, while Group A presented a significant variation in load capacity as a function of print-orientation of the adherends (an increase by approximately 35\% of edgewise direction compared to the flatwise direction), Group B presented only a slight variation in joint properties as a function of printing orientation (the load capacity of flatwise direction printed adherends was $9 \%$ higher compared to edgewise printed parts).

- Modifying the morphology of the adherend surfaces in the overlap region had a more significant influence in the load capacity of the joints with AM adherends than the printing orientation.

\section{ACKNOWLEDGEMENTS}

Authors would like to acknowledge the support of the Brazilian Research Agencies CNPq, FAPERJ and Dow Brasil for supplying the adhesive.

\section{REFERENCES}

[1] *** ASTM Standard F2792, Standard terminology for additive manufacturing technologies, vol. 2012, ASTM International, West Conshohocken, Pa, USA (2012).

[2] Harris M., Potgieter J., Archer R., Arif K. M., Effect of Material and Process Specific Factors on the Strength of Printed Parts in Fused Filament Fabrication: A Review of Recent Developments. Materials, vol. 12(10), 2019, article no. 1664. 
[3] Singh S., Ramakrishna S., Singh R., Material issues in additive manufacturing: A review, Journal of Manufacturing Processes vol. 25, 2017, pp. 185-200.

[4] Hossain M. S., Ramos J., Espalin D., Perez M., Wicker R., Improving tensile mechanical properties of FDMmanufactured specimens via modifying build parameters, International Solid Freeform Fabrication Symposium: An Additive Manufacturing Conference. Austin, TX, vol. 2013, 2013, pp. 380-392.

[5] Solomon A., Rosenthal Y., Ashkenazi D., Stern A., Structure and mechanical behavior of additive manufactured fused deposition modeling ABS, The Annals of "Dunarea de Jos" University of Galati. Fascicle XII: Welding Equipment and Technology, vol. 29, 2018, pp. 47-56.

[6] Banea M. D., da Silva L. F. M., Adhesively bonded joints in composite materials - An Overview, Proceedings of the Institution of Mechanical Engineers Part L, Journal of Materials Design and Applications, vol. 223, no. 1, 2009, pp. 1-18.

[7] Budhe S., Banea M. D., de Barros S., da Silva L. F. M., An updated review of adhesively bonded joints in composite materials, International Journal of Adhesion \& Adhesives, vol. 72, 2017, pp. 30-42.

[8] da Silva L. F. M., Carbas R. J. C., Critchlow G. W., Figueiredo M. A. V., Brown K., Effect of material, geometry, surface treatment and environment on the shear strength of single lap joints, International Journal of Adhesion \& Adhesives, vol. 29, 2009, pp. 621-632.

[9] Banea M. D., Influence of adherend properties on the strength of adhesively bonded joints, MRS Bulletin, vol. 44(8), 2019, pp. 625-629.

[10] Pereira R. B., Morales A. R., Study of mechanical and thermal behavior of PLA modified with nucleating additive and impact modifier, Polimeros vol. 24(2), 2014, pp. 198-202.

[11] Spaggiari A., Denti F., Mechanical strength of adhesively bonded joints using polymeric additive manufacturing, Proceedings of the Institution of Mechanical Engineers, Part C:
Journal of Mechanical Engineering Science, 2019.

[12] Boss J. N., Ganesh V. K., Lim C. T., Modulus grading versus geometrical grading of composite adherends in single-lap bonded joints, Compos. Struct. vol. 62, 2003, pp. 113-121.

[13] dos Reis M., Banea M. D., da Silva L. F. M., Carbas R. J. C., Mechanical characterization of a modern epoxy adhesive for automotive industry, Journal of the Brazilian Society of Mechanical Sciences and Engineering, vol. 41, 2019, article no. 340.

[14] Bonaldo J., Banea M. D., Carbas R. J. S., da Silva L. F. M., de Barros S., Functionally graded adhesive joints by using of thermally expandable particles, Journal of Adhesion, vol. 95, 2019, pp. 995-1014.

[15] ***ASTM D1002 - 10, Standard Test Method for Apparent Shear Strength of Single-Lap-Joint Adhesively Bonded Metal Specimens by Tension Loading (Metal-to-Metal), vol. 15.06, ASTM International, West Conshohocken, Pa, USA, 2019.

[16] Banea M. D., da Silva L. F. M., Campilho R. D.S. G., Moulds design for adhesive bulk and joint specimens manufacturing, Assembly Automation, vol. 32(3), 2012, pp. 284 - 292.

[17] Razavi S. M., Berto F., Peron M., Torgersen J., Parametric study of adhesive joints with non-flat sinusoid interfaces, Theoretical and Applied Fracture Mechanics. vol. 1, 2018, pp. 44-55.

[18] Ávila A. F., de O. Bueno P., Stress analysis on a wavy-lap bonded joint for composites, International Journal of Adhesion and Adhesives, vol. 24 (5), 2004, pp. 407-414.

[19] Afrose M. F., Masood S. H., Iovenitti P., Nikzad M., Sbarski I. Effects of part build orientations on fatigue behaviour of FDMprocessed PLA material, Progress in Additive Manufacturing, vol. 1 (1-2), 2016, pp. 21-28.

[20] Kovan V., Altan G., Topal E. S., Effect of layer thickness and print orientation on strength of $3 D$ printed and adhesively bonded single lap joints, Journal of Mechanical Science and Technology, vol. 31, 2017, pp. 2197. 